\title{
The role of MMP-9 in the anti-angiogenic effect of secreted protein acidic and rich in cysteine
}

\author{
P Bhoopathi', C Chetty', M Gujrati' ${ }^{2}$ DH Dinh ${ }^{3}$, JS Rao ${ }^{1,3}$ and SS Lakka*,I \\ 'Program of Cancer Biology, Department of Cancer Biology and Pharmacology, University of Illinois College of Medicine at Peoria, One Illini Drive, Peoria, \\ IL 61605, USA; ${ }^{2}$ Department of Pathology, University of Illinois College of Medicine at Peoria, One Illini Drive, Peoria, IL 6I 605, USA; ${ }^{3}$ Department of \\ Neurosurgery, University of Illinois College of Medicine at Peoria, One Illini Drive, Peoria, IL 6I605, USA
}

BACKGROUND: Secreted protein acidic and rich in cysteine (SPARC), a matricellular glycoprotein, modulates cellular interaction with the extracellular matrix and is capable of altering the growth of various cancers. We therefore sought to determine the effect of SPARC expression on medulloblastoma tumour growth and angiogenesis.

METHODS: To this extent, we selected three SPARC full-length cDNA overexpressed clones (Daoy-SP). Consequences of SPARC overexpression were studied in terms of cell growth, angiogenesis using co-culture assay in vitro, dorsal skin-fold chamber assay in vivo, PCR Array for human angiogenic genes, as well as western blotting for angiogenic molecules and tumour growth, in an orthotopic tumour model.

RESULTS: The SPARC protein and mRNA levels were increased by approximately three-fold in Daoy-SP cells compared with parental (Daoy-P) and vector (Daoy-EV) controls. Daoy-SP clones reduced tumour cell-induced angiogenesis in vitro and in vivo, and formed small tumours with fewer blood vessels when compared with controls. Matrix metalloprotease-9 (MMP-9) and vascular endothelial growth factor (VEGF) expression were decreased in Daoy-SP clones. Further, inhibition of MMP-9 expression caused SPARCmediated inhibition of angiogenesis and tumour growth as MMP-9 rescued SPARC-mediated anti-angiogenic effect in vitro and tumour growth inhibition in vivo.

CONCLUSION: Overexpression of SPARC decreases angiogenesis, which leads to decreased tumour growth. Further, the role of MMP-9 could be attributed to the anti-angiogenic effect of SPARC.

British Journal of Cancer (2010) I 02, 530-540. doi:I0.I038/sj.bjc.6605538 www.bjcancer.com

Published online 19 January 2010

(c) 2010 Cancer Research UK

Keywords: angiogenesis; SPARC; VEGF; MMP-9; CD-3I

Medulloblastoma (MB) is a malignant embryonal tumour that is predominantly diagnosed in children and continues to pose a difficult clinical management problem. Medulloblastomas occur principally in the midline cerebellar region but are prone to invade the meninges and cerebrospinal fluid spaces. With aggressive surgery, craniospinal radiotherapy and chemotherapy, only slightly $>50 \%$ of children diagnosed with medulloblastoma are disease free after 5 years (Eberhart et al, 2002; Guerreiro et al, 2008; Packer and Vezina, 2008). Furthermore, current treatment for medulloblastoma carries a high risk of long-term morbidity, with the majority of patients having some degree of hormonal, auditory and neurocognitive impairment (Ris et al, 2001). Even with conventional chemotherapy and radiotherapy, only a subset of patients are cured; thus, a great need for new therapeutic approaches exists (Packer, 1999; Zeltzer et al, 1999). Similar to many other central nervous tumours, some PNET/MB tumours show marked neovascularisation (Assimakopoulou et al, 1997). Medulloblastomas produce a wide range of angiogenic factors that are, either individually or together, likely to have a direct role in tumour growth, tumour progression and angiogenesis (Pavlakovic

*Correspondence: Dr SS Lakka; E-mail: slakka@uic.edu

Revised I December 2009; accepted 16 December 2009; published online 19 January 2010 et al, 2001a). Previous reports indicate that assessment of angiogenesis by microvessel density and quantification is significantly higher in medulloblastomas associated with poor prognosis (Ozer et al, 2004).

Secreted protein acidic and rich in cysteine (SPARC/ osteonectin/BM-40) is a secreted macromolecule that interacts with cell-surface receptors, the extracellular matrix (ECM) and/or growth factors and proteases (Bornstein and Sage, 2002). The role of SPARC in tumourigenesis is complex and seems to be cell-type specific owing to its diverse functions in a given microenvironment. Solid tumours in SPARC-null mice grew significantly larger than those in wild-type animals (Brekken et al, 2003). The SPARC functions as a tumour suppressor in neuroblastoma, breast, pancreatic, lung and ovarian cancers (Framson and Sage, 2004). In addition, SPARC modulates angiogenesis and regulates the production, assembly and organisation of the ECM (Sage et al, 1984; Bradshaw and Sage, 2001). By directly binding to vascular endothelial growth factor (VEGF), SPARC inhibits microvascular endothelial cell proliferation stimulated by $\mathrm{VEGF}_{165}$, indicating that it has anti-angiogenic activity (Yan and Sage, 1999; Chlenski et al, 2006; Chandrasekaran et al, 2007). The SPARC binds to VEGF, thus inhibiting VEGF interaction with endothelial cell surface, VEGFR1 autophosphorylation, ERK1/2 activation and VEGF-induced DNA synthesis (Kupprion et al, 1998). The SPARC 
also binds platelet-derived growth factor-AB (PDGF-AB) and PDGF-BB on endothelial cells and inhibits the interaction of these growth factors with their tyrosine kinase receptors (Raines et al, 1992). In addition, SPARC influences the levels and activity of several angiogenic molecules (e.g., PDGF, fibroblast growth factor-2 (FGF-2), VEGF and insulin-like growth factor) (Francki et al, 1999, 2003; Brekken and Sage, 2001). Further, SPARC can inhibit angiogenesis indirectly by regulating the expression of other angiogenesis-related genes, such as matrix metalloproteases (MMPs) (Shankavaram et al, 1997) and transforming growth factor- $\beta 1$ (Francki et al, 1999). However, its role in tumourinduced angiogenesis seems to be tumour specific. Recent studies demonstrate that overexpression of SPARC led to a significant decline in microvessel density, resulting in delayed tumour formation and reduction in tumour size in hepatocellular carcinoma xenografts (Lau et al, 2006). The SPARC blocks angiogenesis in vitro and in vivo in neuroblastoma and is one of the key contributors to the anti-angiogenesis activity of the Schwann cell-conditioned medium (Chlenski et al, 2002). However, other studies point to the pro-angiogenic activity of SPARC. For example, SPARC was found high levels in breast cancer, colon cancer (Bellahcene and Castronovo, 1995; Porte et al, 1995), metastatic melanoma (Ledda et al, 1997) and invasive meningioma (Rempel et al, 1999).

In this study, we examined the effects of SPARC on medulloblastoma tumours in vitro and in vivo and whether inhibition of angiogenesis is implicated in the anti-tumour effect of SPARC. To elucidate the role of SPARC, we enhanced SPARC expression in medulloblastoma cells using stable transfection and expression constructs with SPARC full-length cDNA driven by a CMV promoter. We developed three human medulloblastoma cell lines designated as Daoy-SP1/2/3, which stably express human SPARC cDNA. The SPARC expression reduced xenograft growth with reduced vascularity in an orthotopic medulloblastoma model. We also demonstrated that SPARC expression inhibits VEGF-mediated angiogenesis by altering MMP-9 expression, thereby leading to reduced angiogenesis.

\section{MATERIALS AND METHODS}

\section{Antibodies and reagents}

Antibodies against SPARC, VEGF, epidermal growth factor receptor, fibroblast growth factor receptor (FGFR), PDGFR, VEGFR2, CD31, MMP-9 and major histocompatibility complex (MHC) class-I (Santa Cruz Biotechnology, Santa Cruz, CA, USA); Von-Willebrand factor (Factor-VIII) (DAKO Corp., Carpinteria, CA, USA); and MHC class-I antibody for immunohistochemistry (Serotec, Inc., Raleigh, NC, USA) were used. The RT ${ }^{2}$ PCR Array for angiogenesis (SA Biosciences, Frederick, MD, USA) was also used in this study. All other reagents were of analytical grade or better.

\section{Daoy cell culture}

Daoy cells were obtained from ATCC (Manassas, VA, USA) and cultured in Advanced-MEM supplemented with $5 \%$ foetal bovine serum, $2 \mathrm{mMl}^{-1}$ L-glutamine, 100 units $\mathrm{ml}^{-1}$ of each penicillin and $100 \mu \mathrm{g} \mathrm{ml}^{-1}$ streptomycin. Cells were maintained in a humidified atmosphere containing $5 \% \mathrm{CO}_{2}$ at $37^{\circ} \mathrm{C}$.

\section{Construction of pcDNA3.1-SPARC and transfection of Daoy cells}

An 1100-bp cDNA fragment of human SPARC was amplified by PCR using synthetic primers and sub-cloned into a pcDNA3.1 vector (Invitrogen, San Diego, CA, USA) in sense orientation. Daoy cells were transfected with full-length cDNA of SPARC containing vector or empty vector using FuGene HD (Roche, Indianapolis, IN, USA) as described earlier (Mohanam et al, 2001). Stable transfectants were selected with cloning cylinders after 3-4 weeks in medium containing G418. Wild-type Daoy cells are termed as Daoy parental (Daoy-P) and the stable cell lines overexpressing SPARC were designated as Daoy-SP, whereas Daoy-EV was the cell line transfected stably with the empty vector.

\section{Immunofluorescence microscopy}

We used a previously described protocol with minor changes (Chetty et al, 2007). Briefly, cells were cultured on eight-well chamber slides and fixed with $4 \%(\mathrm{w} / \mathrm{v})$ paraformaldehyde in phosphate-buffered saline (PBS), permeabilised with $0.1 \%(\mathrm{w} / \mathrm{v})$ Triton X-100 in PBS and blocked with $1 \%(\mathrm{w} / \mathrm{v})$ bovine serum albumin in PBS for $1 \mathrm{~h}$ at $4^{\circ} \mathrm{C}$. Cells were incubated overnight either with anti-SPARC or with anti-Von-Willebrand factor antibody $\left(1: 100\right.$ dilution) at $4{ }^{\circ} \mathrm{C}$, followed by the corresponding Texas Red/fluorescent isothiocyanate ( $1: 200$ dilution)-conjugated secondary antibody for $1 \mathrm{~h}$, and mounted with mounting medium containing 4,6-diamidino-2-phenylindole. The results were documented using a fluorescence microscope.

\section{Western blotting}

Western blot analysis was performed as described previously (Bhoopathi et al, 2008). Briefly, $36 \mathrm{~h}$ after seeding, Daoy-P, Daoy-EV and Daoy-SP cells were collected and lysed in RIPA buffer. Equal amounts of proteins were resolved on SDSpolyacrylamide gel electrophoresis and transferred onto a PVDF membrane. The blot was blocked with $5 \%$ non-fat dry milk and probed overnight with primary antibodies (1:1000 dilution), followed by horseradish peroxidase-conjugated secondary antibodies (1:2500 dilution). An ECL system was used to detect chemiluminescent signals. All blots were re-probed with GAPDH antibody to confirm equal loading.

\section{siRNA design and transient transfection}

The SPARC small interfering RNA (siRNA) sequences were designed with the help of a siRNA designer programme (Imgenex, Sorrento Valley, CA, USA). The siRNA was complementary to an exonic sequence of the target mRNA and compatible with the pcDNA3.1 vector (Invitrogen, San Diego, CA, USA). The following siRNA sequence $5^{\prime}$ - TCGAGGGTGTGCAGCAATGACAACAAGA GTCGTCGTTGTTGTCATTGCTGCACACCG- $3^{\prime}$ was used to construct SPARC siRNA. A control vector containing siRNA with a scrambled sequence was constructed and designated as pSV. We used the following scrambled sequence: $5^{\prime}$-CACGGAGGTTG CAAAGAATAATCGATTATTCTTTGCAACCTCCGTGC-3' . FuGene HD transfection reagent (Roche; $1 \mu \mathrm{g}$ plasmid: $3 \mu \mathrm{l}$ of FuGene HD) was used for transfections as per the manufacturer's instructions. After transfection, the cells were cultured in Advanced-MEM with $5 \%$ foetal bovine serum for $24 \mathrm{~h}$, rinsed once with PBS and cultured for an additional $16 \mathrm{~h}$ in serum-free Dulbecco's modified Eagle's medium/F12 50/50. Conditioned medium and cell lysates were collected, and MMP-9 and SPARC levels were determined by gelatin zymography and western blot analysis, respectively.

\section{Reverse transcriptase PCR}

Daoy-P, Daoy-EV and Daoy-SP cells were grown for $36 \mathrm{~h}$. Total RNA was extracted from these cells and cDNA was synthesised using poly-dT primers as described earlier (Chetty et al, 2008). PCR was performed using the following primers: SPARC, $5^{\prime}$-GGAAGAAACTGTGGCAGAGG- $3^{\prime}$ (sense) and $5^{\prime}$-ATTGCTGC ACACCTTCTCAA-3' (antisense); GAPDH, 5'-TGAAGGTCGGAG TCAACGGATTTGGT- $3^{\prime}$ (sense) and $5^{\prime}$-CATGTGGGCCATGAGG 
TCCACCAC-3' (antisense). Quantification of SPARC mRNA levels was carried out by densitometry.

\section{Cell proliferation assays}

Cell proliferation was determined using a 3-(4,5-dimethylthiazol2-yl)-2,5-diphenyl-2H-tetrazolium bromide (MTT) assay (R\&D Systems, Minneapolis, MN, USA) as previously described (Rao et al, 2007). Briefly, Daoy-P, Daoy-EV and Daoy-SP (SP1, SP2 and SP3) cells (5000 cells per well) were seeded in 96-well cell culture plates and incubated up to $60 \mathrm{~h}$. After $0-60 \mathrm{~h}$, MTT reagent was added, incubated for $4 \mathrm{~h}$ at $37^{\circ} \mathrm{C}$ and the absorbance of formazan was measured with a microplate reader at $A_{550}$.

\section{In vitro angiogenesis assay}

Tumour cell-induced microtubule network formation was determined as described previously (Gondi et al, 2004). Daoy-P, Daoy-EV and Daoy-SP cells $\left(2 \times 10^{4}\right.$ per well $)$, either with SPARC siRNA, anti-SPARC antibody treatment or alone, were seeded in eight-well chamber slides and allowed to grow for $24 \mathrm{~h}$. Thereafter, the medium was removed and HMEC cells $\left(4 \times 10^{4}\right.$ cells per well $)$ were added. After $36 \mathrm{~h}$ of co-culture, cells were stained with factorVIII antigen. The formation of tubular capillary-like structures, which is an indicator of angiogenesis, was assessed by confocal microscopy. Image Pro Discovery software (Media Cybernetics, Inc., Bethesda, MD, USA) was used to quantify the tube length.

\section{Dorsal skin-fold chamber model}

In vivo angiogenesis assay was performed as described previously (Lakka et al, 2005). Briefly, Daoy-P, Daoy-EV and Daoy-SP cells $\left(1 \times 10^{6}\right.$ cells in $\left.100 \mu \mathrm{l}\right)$ were injected into diffusion chambers (Fisher, Pittsburg, PA, USA) and sealed with bone wax. Athymic nude female mice (4-6 weeks old; five per group) were anaesthetised with ketamine: xylazine $\left(100: 10 \mathrm{mg} \mathrm{kg}^{-1}\right)$. A dorsal air sac was created by subcutaneously injecting $5 \mathrm{ml}$ of air, and a superficial incision was made at the edge of the air sac through which the chambers were placed underneath the skin. After 10 days, the animals were killed and the skin area covering the chambers was removed and photographed. The number of tumour cell-induced blood vessels was counted in five different fields as described previously (Lakka et al, 2005).

\section{$\mathrm{RT}^{2}$ profiler PCR array}

Total RNA was isolated from Daoy-P, Daoy-EV and Daoy-SP cells and cDNA was synthesised as described above. The human angiogenesis signalling pathway $\mathrm{RT}^{2}$ Profiler PCR Array was used to profile the expression of 84 genes related to the angiogenesis signalling pathway, according to manufacturer's instructions. The fold change of mRNA expression was calculated on the basis of the cycle threshold $\left(C_{\mathrm{t}}\right)$ values obtained from the real-time PCR experiment. The scatter plot of test $v s$ control samples indicated the validity of the experiment.

\section{Intracranial tumour model and immunohistochemistry}

All animal experiments were carried out after obtaining approval from the Institutional Animal Care and Use Committee on a project-specific basis in accordance with the Public Health Service Policy on Humane Care and Use of Laboratory Animals (PHS Policy), and meet the standards required by the UKCCCR guidelines (Workman et al, 1988). Animals were housed in pathogen-free conditions in a light/dark cycle of $12 / 12 \mathrm{~h}$ and fed with rodent chow and water ad libitum. Daoy cells with or without treatments $\left(1 \times 10^{5}\right.$ cells, six animals per group, Daoy-P, Daoy-EV, Daoy-SP2, Daoy-EV + pcMMP9 and Daoy-SP2 + pcMMP-9 cells) were stereotactically implanted as described previously (Bhoopathi et al, 2008). Animals were monitored for 180 days, which was the designated termination point of the experiment. Animals who lost $>20 \%$ of body weight or had trouble ambulating, feeding or grooming were killed. For histological analysis, brains were snap frozen and maintained at $-70^{\circ} \mathrm{C}$ until sectioning. Tumour volume was assessed as described previously (Ding et al, 2005). Briefly, all brains were serially sectioned, and $8-\mu \mathrm{m}$ sections were incubated with $\mathrm{mAb}$ anti-human-specific MHC class-I IgG $\left(10 \mu \mathrm{g} \mathrm{ml}^{-1}, 2 \mathrm{~h}\right.$, at $4^{\circ} \mathrm{C} ; \mathrm{mAb} \mathrm{W6/32}$, Serotec, Inc.), followed by a multi-link secondary antibody conjugated to biotin and horseradish peroxidase, followed by incubation with streptavidin, and then $3,3^{\prime}$-diaminobenzidine substrate (Sigma, St Louis, MO, USA). Digital images were imported into Adobe Photoshop (San Jose, CA, USA), stained areas in each section were quantified as a pixel number and pixel numbers for all sections from each brain were summed to obtain a total pixel number. Excised brains were fixed in $10 \%$ buffered formalin and embedded in paraffin. Tissue sections ( $5 \mu \mathrm{m}$ thick) were obtained from the paraffin blocks and were stained with haematoxylin and eosin using standard histological techniques. For immunohistochemical analysis, sections were incubated with $\mathrm{mAb}(1 \mathrm{~h}, \mathrm{RT})$, followed by the appropriate secondary antibody. For horseradish peroxidase-conjugated secondary antibody incubation, we used 3,3'-diaminobenzidine solution as chromogen. Nucleus was counterstained with either haematoxylin or 4,6-diamidino-2-phenylindole. Negative control slides were obtained by nonspecific IgG. Sections were mounted with mounting solution and analysed using an inverted microscope.

\section{Statistical analysis}

All data are expressed as mean \pm s.e. Statistical analysis was performed using Student's $t$-test or a one-way analysis of variance. A $P$-value of $<0.05$ was considered statistically significant. All experiments were performed in triplicate with consistent results.

\section{RESULTS}

\section{Overexpression of SPARC in Daoy cells}

The SPARC, a prototype of the matricellular protein family, was shown to have an important role in various aspects of tumourigenesis, including tumour invasion, angiogenesis and tumour growth. To experiment with a genetic approach to induce SPARC expression and observe its effects on medulloblastoma tumour growth in vitro and in vivo, we cloned a human SPARC cDNA in a pcDNA3.1 mammalian expression vector and transfected it into Daoy parental (Daoy-P) cells. The stable cell lines overexpressing SPARC were designated as Daoy-SP, whereas the stable cell line expressing the empty vector (pcDNA3.1) was designated as Daoy-EV. We randomly tested clones for mRNA expression of SPARC transcript (data not shown) and selected three SPARC-overexpressed stable clones. Figure 1A indicates that SPARC transcript levels were increased in the three clones tested when compared with parental and vector controls. There was about a three-fold increase in mRNA transcript levels in Daoy-SP clones (Daoy-SP1, Daoy-SP2 and Daoy-SP3; $P<0.01$ vs controls; Figure 1B). To confirm that this upregulation of SPARC mRNA translated into increased levels of SPARC protein, we next performed western blot and immunocytochemical analyses for SPARC expression in these three Daoy-SP clones. We found a three- to four-fold increase in SPARC expression in Daoy-SP clones compared with parental and empty vector controls $(P<0.01$; Figure 1B). As assessed by immunofluorescence microscopy, the distribution of SPARC indicated intense staining in all three Daoy-SP clones, compared with Daoy-P and Daoy-EV controls (Figure 1C). 

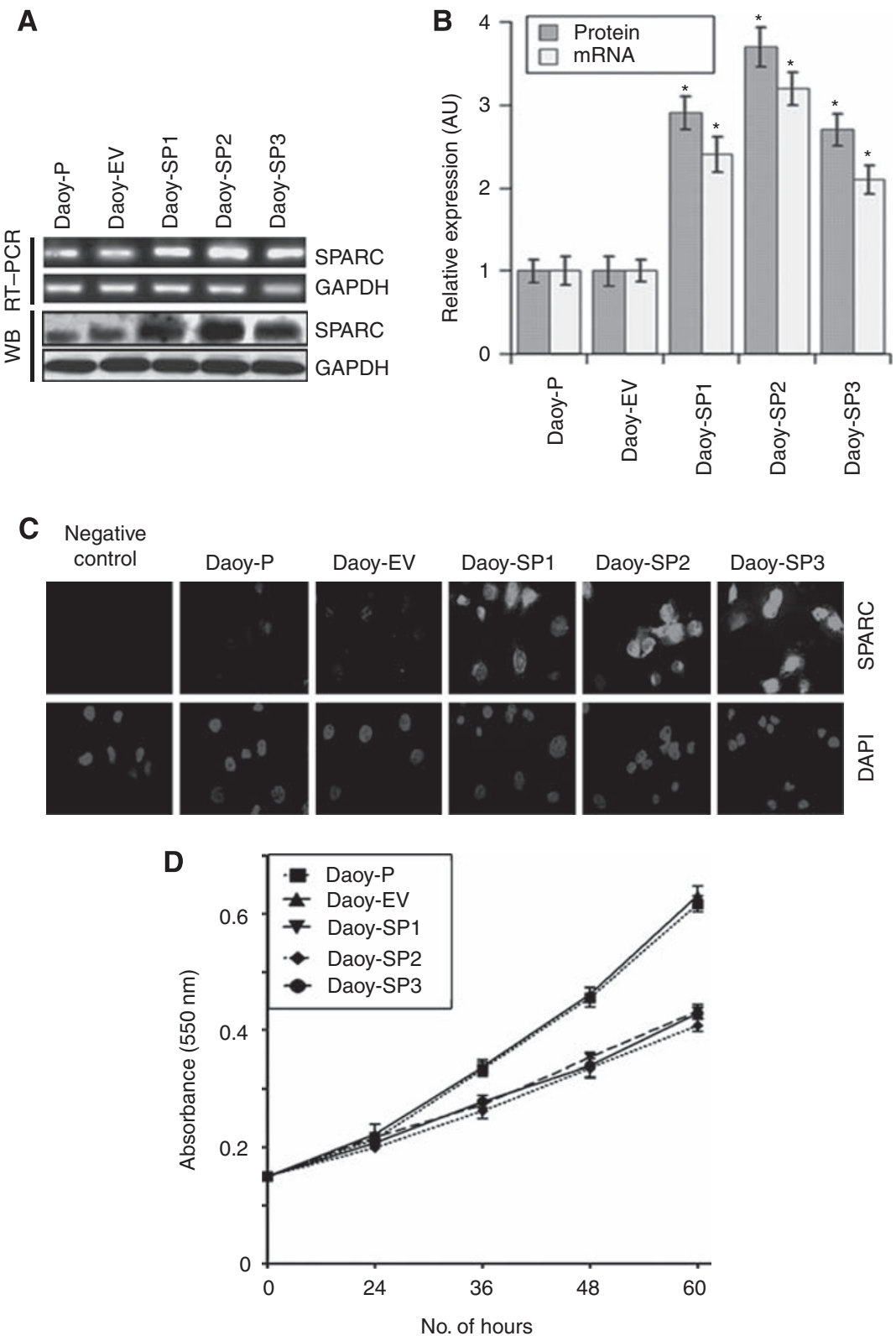

Figure I Overexpression of secreted protein acidic and rich in cysteine (SPARC) in Daoy medulloblastoma cells inhibits Daoy cell proliferation. Daoy cells were stably transfected with plasmid containing full-length SPARC cDNA and empty vector. (A) Total RNA was extracted using Trizol reagent, and reverse transcriptase PCR was performed for assessment of SPARC mRNA transcript level. GAPDH served as a control for RNA quality. SPARC protein levels were determined in total cell lysates by western blot analysis using SPARC-specific antibody. GAPDH was used to confirm equal loading of cell lysates. (B) Protein and mRNA transcripts level were quantified by densitometric analysis as shown in the corresponding bar graph. Columns, mean of triplicate experiments; bars, s.e.; $* P<0.01$, significant difference from Daoy-P control cells. (C) Immunocytochemical analysis for SPARC in different SPARC-overexpressed clones. Mouse IgG was used as negative control. (D) Daoy-P. Daoy-EV and Daoy-SP cells (5000 cells) were plated in 96 well plates, incubated for $0-60 \mathrm{~h}$ and $20 \mu \mathrm{l}$ of $0.5 \mathrm{mg} \mathrm{ml}^{-1} 3$-(4,5-dimethylthiazol-2-yl)-2,5-diphenyl-2H-tetrazolium bromide (MTT) in phosphate-buffered saline (PBS) were added to cells. The cells were incubated for another $4 \mathrm{~h}$. Next, the medium was removed from each well and dimethyl sulphoxide (DMSO) $(\mid 00 \mu \mathrm{l})$ was added to each well to dissolve the formazan crystals. Absorbance values at $550 \mathrm{~nm}$ were measured with a microplate reader and the results were presented with the comparison of cells treated with vehicle. Points, mean of triplicate experiments; bars, s.e.

\section{Overexpression of SPARC decreases Daoy cell proliferation}

To determine whether SPARC overexpression affected the growth of Daoy cells, the growth rates of SPARC-overexpressed cells were compared with those of parental and empty vector controls. A very minimal decrease in proliferation was observed at $24 \mathrm{~h}(5-8 \%)$. At $48 \mathrm{~h}$, there was an $\sim 15 \%$ decrease in proliferation in all three SPARC-overexpressed clones, compared with Daoy-P and Daoy-EV cells. Finally, at $60 \mathrm{~h}$, there was a 24,30 and $25 \%$ inhibition of Daoy-SP1, Daoy-SP2 and Daoy-SP3 cells, respectively, compared with Daoy-P and Daoy-EV cells (Figure 1D).

\section{SPARC decreases tumour-induced angiogenesis in vitro and in vivo}

Previous studies indicate that purified SPARC blocked endothelial cell migration in a dose-dependent manner in PNET tumours (Chlenski et al, 2002). To confirm this effect in SPARC-overexpressed 
A
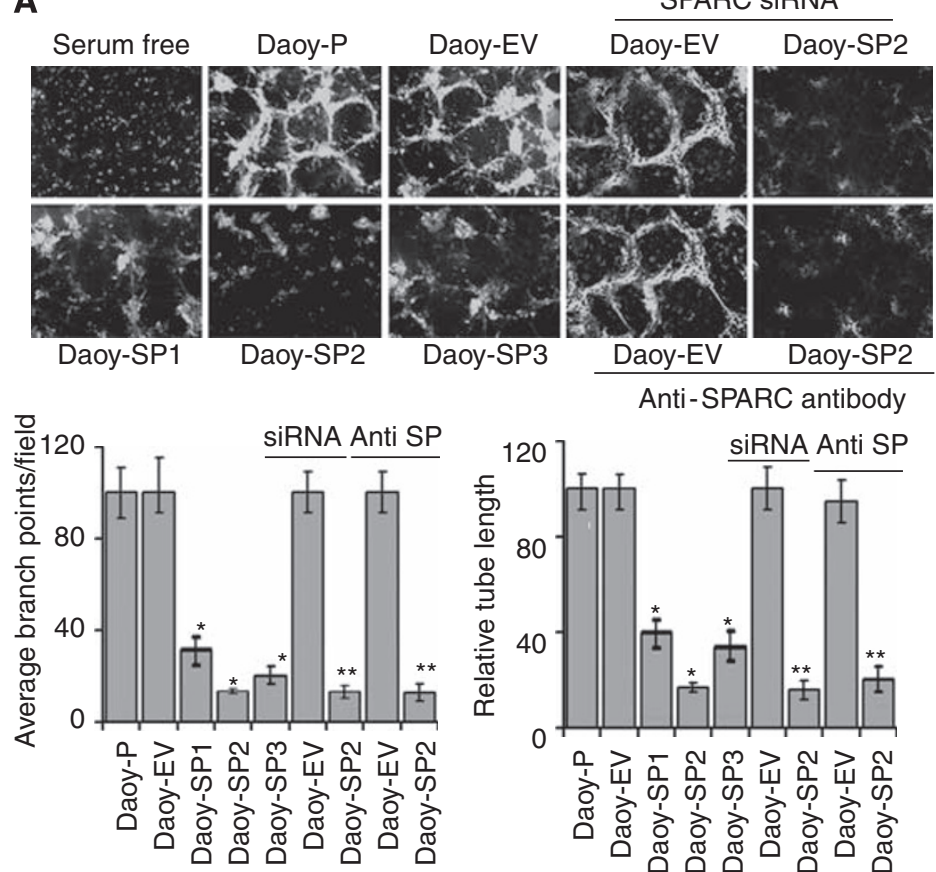

B
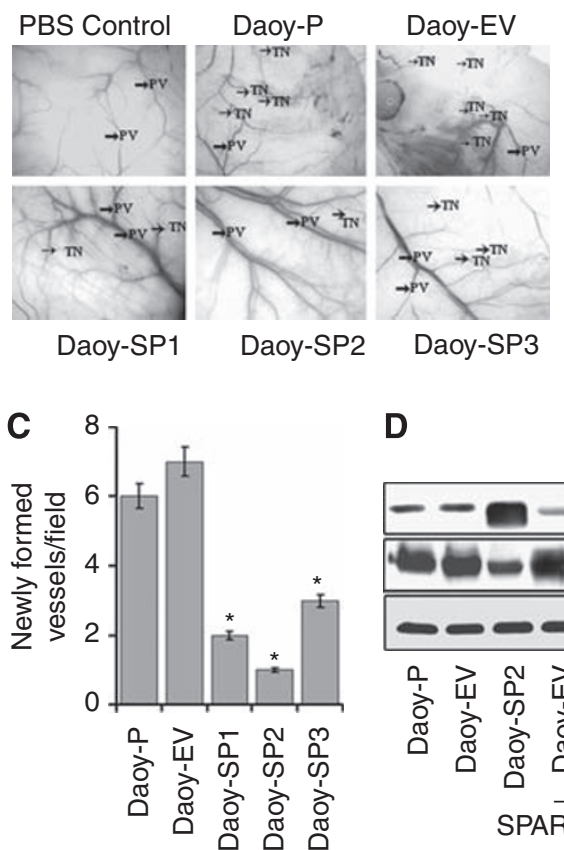

D

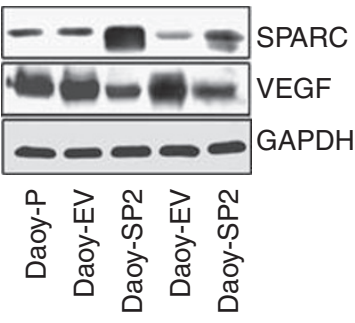

SPARC SIRNA

Figure 2 Overexpression of secreted protein acidic and rich in cysteine (SPARC) in Daoy cells inhibits tumour-induced angiogenesis in vitro and in vivo. (A) In vitro angiogenesis: Daoy-P, Daoy-EV and Daoy-SP cells $\left(2 \times 10^{4}\right.$ per well), either with SPARC siRNA treatment or with anti-SPARC antibody treatment, were seeded in eight-well chamber slides. After $24 \mathrm{~h}$, the medium was removed and $4 \times 10^{4} \mathrm{HMEC}$ cells were added. The cells were allowed to co-culture for $36 \mathrm{~h}$ the cells were fixed and performed immunofluorescence for factor-VIII as described in the 'Materials methods' section and observed for angiogenic response. Relative branch points and relative tube length were quantified as described in the 'Materials and methods' section. Columns, mean of triplicate experiments; bars, s.e.; $* P<0.0$ I, significant difference from Daoy-P cells; $* * P<0.01$, significant difference from Daoy-EV cells treated with SPARC siRNA or anti-SPARC antibody (siRNA = SPARC siRNA; anti-SP = anti-SPARC antibody). (B) In vivo angiogenesis: Daoy-P, Daoy-EV and Daoy-SP cells $\left(I \times 10^{6}\right)$ were implanted into diffusion chambers and were surgically placed underneath the dorsal skin of athymic nude mice as described in the 'Materials and Methods' section. PV, pre-existing vasculature; TN, tumour-induced vasculature. (C) Newly formed vessels were quantified and represented as per field. Columns, mean of triplicate experiments; bars, s.e.; ${ }^{*} P<0.01$, significant difference from Daoy-EV cells. (D) Western blot analysis showing SPARC and vascular endothelial growth factor (VEGF) levels with the treatment of siRNA against SPARC. GAPDH served as loading control.

Daoy cells, cells were grown for $24 \mathrm{~h}$ and then co-cultured with endothelial cells in an in vitro angiogenic assay as described in the 'Materials and methods' section; cell number was corrected for $5-8 \%$ inhibition at the $24 \mathrm{~h}$ time point in cell growth in Daoy-SP clones as compared with controls. Daoy-P and Daoy-EV cells cultured with endothelial cells elicited a strong angiogenic response and induced HMECs to differentiate into capillary-like structures within $36 \mathrm{~h}$. In contrast, microvessel morphogenesis was impeded in the cocultures of HMECs and Daoy-SP clones. Quantification indicated a $75-80 \%$ decrease in the formation of branch points and a $60-75 \%$ decrease in vessel length in HMEC cells cultured with Daoy-SP clones, compared with HMEC cells cultured with Daoy-P and Daoy-EV (Figure 2A).

We also examined whether Daoy-SP clones could inhibit tumour angiogenesis in vivo as assessed by the dorsal window model. Implantation of a chamber containing Daoy-P and Daoy-EV cells in the dorsal skin-fold chamber resulted in the development of tumour-induced microvessels (TN) with curved thin structures and many tiny bleeding spots. In contrast, implantation of Daoy-SP cells (cell number corrected for growth inhibition) had a $50-75 \%$ decrease in tumour-induced microvessels, compared with Daoy-P and Daoy-EV cells (Figures 2B and C).

To further test the effect of increased expression of SPARC on angiogenesis in vitro, we inhibited SPARC expression using siRNA or antibody against SPARC in Daoy-SP cells and tested their ability to induce endothelial cell network formation. Figure 2D indicates that SPARC expression in SPARC siRNA-transfected Daoy-SP cells was decreased compared with that in Daoy-SP cells and was comparable with that of Daoy-P parental controls. However, as shown in Figure 2A, siRNA against SPARC or anti-SPARC antibody could not restore Daoy-SP tumour cell-induced angiogenesis. Taken together, these data suggest that the decreased angiogenesis in SPARC-overexpressed cells could be because of SPARC-induced altered cellular composition rather than the effect of SPARC expression itself.

\section{Overexpression of SPARC modulates angiogenic factors}

To better determine the mechanisms underlying SPARC-mediated inhibition of angiogenesis, we used the human angiogenesis signalling pathway $\mathrm{RT}^{2}$ Profiler PCR Array to profile the expression of 84 genes related to the angiogenesis signalling pathway. Total RNA from Daoy-P, Daoy-EV and Daoy-SP2 cells (Daoy-SP2 cells exhibited higher anti-angiogenic effect than Daoy-SP1 and Daoy-SP3) was used to synthesise cDNA. Real-time PCR was performed as per the manufacturer's instructions and fold change of mRNA expression was calculated on the basis of $C_{\mathrm{t}}$ values. The scatter plot of the test (Daoy-SP2) vs control (Daoy-EV) samples indicates the validity of the experiment (Figure 3A). It is evident from the results that SPARC overexpression led to decreased expression of pro-angiogenic factors (e.g., VEGF, FGFR, ECGF and MMP-9), as well as increased expression of anti-angiogenic factors (e.g., TIMP-3 and transforming growth factor- $\beta$; Figure $3 \mathrm{~B}$ ). To confirm the PCR array results, protein levels of pro-angiogenic molecules in cell lysates from Daoy-P, Daoy-EV and Daoy-SP2 cells were assessed using western blotting (Figure 3C). When adjusted for parental controls, densitometry analysis revealed a 65, 78 and $70 \%$ decrease in 

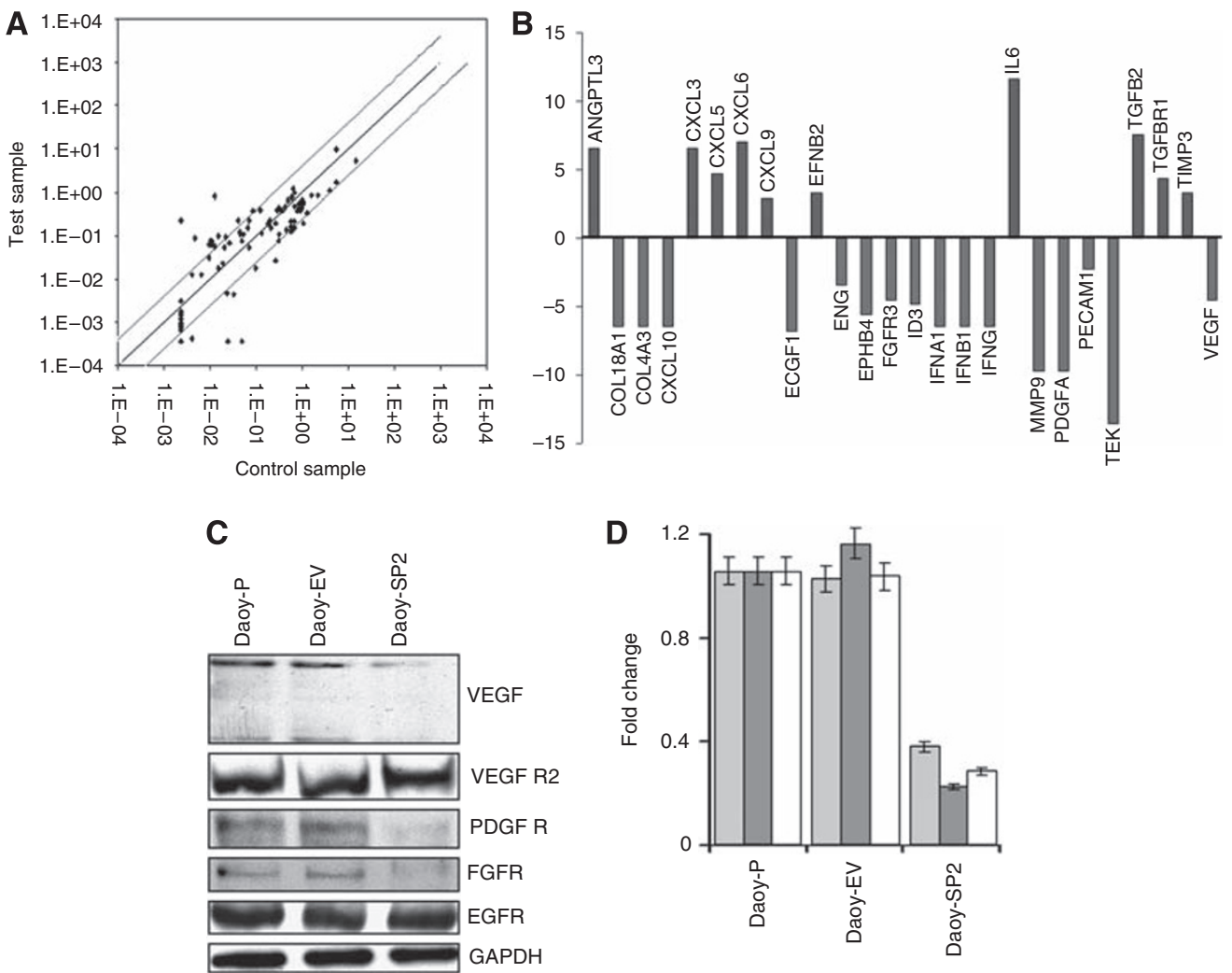

Figure $3 R T^{2}$ profiler PCR array for angiogenic factors in secreted protein acidic and rich in cysteine (SPARC)-overexpressed Daoy cells. We used the human angiogenesis signalling pathway $\mathrm{RT}^{2}$ Profiler PCR Array to profile the expression of 84 genes related to the angiogenesis signalling pathway. (A) The scatter plot of the test vs control samples indicates the validity of the experiment. (B) Graph showing decreased expression of several angiogenic factors and increased expression of anti-angiogenic factors. (C) Daoy-P, Daoy-EV and Daoy-SP2 cell lysates were used to perform western blot analysis for the angiogenic growth factors, i.e. vascular endothelial growth factor (VEGF), VEGFR2, platelet-derived growth factor receptor (PDGFR), fibroblast growth factor receptor (FGFR) and epidermal growth factor receptor (EGFR). GAPDH served as a loading control. (D) Protein levels were quantified by densitometry as shown in the corresponding bar graph. All experiments were performed in triplicate with consistent results. Columns, mean of triplicate experiments; bars, s.e.; $* P<0.0$ l, significant difference from Daoy-P cells.

VEGF, PDGFR and FGFR, respectively, in Daoy-SP2 cells compared with controls (Figure 3D). The VEGFR2 and epidermal growth factor receptor expression remained unchanged (Figures $3 \mathrm{C}$ and $\mathrm{D})$.

\section{Overexpression of SPARC inhibits MMP-9-mediated angiogenesis activity and VEGF levels}

The SPARC and MMP-9 are known to interact to regulate many stages of tumour progression including ECM deposition, angiogenesis and metastasis (Arnold et al, 2008). In addition, as mentioned above, the $\mathrm{RT}^{2}$ Profiler PCR Array for angiogenesis and western blot analysis showed that SPARC overexpression led to decreased expression of MMP-9 and VEGF (Figure 3B). We therefore examined the possible role of MMP-9 in the antiangiogenic effect of SPARC-overexpressed Daoy medulloblastoma cells. Our results show that MMP-9 activity and protein expression were decreased in Daoy-SP2 cells, compared with Daoy-P and Daoy-EV cells (Figure 4A). In addition, the expression of VEGF, which has an essential role in endothelial proliferation and angiogenesis, was also decreased in Daoy-SP2 cells compared with parental and vector controls. We next examined the ability of MMP-9 expression in Daoy-SP2 cells to induce angiogenesis in vitro. Figure 4B indicates that ectopic expression of MMP-9 using a vector expressing full-length MMP-9 cDNA in Daoy-SP2 cells induced MMP-9 expression, which is comparable to that of parental Daoy-P cells. Further, VEGF expression was also induced in these cells, indicating that VEGF expression is dependent on
MMP-9 expression in SPARC-overexpressed cells (Figure 4A). To elucidate the role of MMP-9 in SPARC-mediated inhibition of tumour cell-induced angiogenesis, we performed real-time PCR array for angiogenesis and western blot analysis with MMP-9 overexpression in Daoy-SP cells (Daoy-P vs Daoy-SP2 + pcMMP9). The results indicated that MMP-9 overexpression in Daoy-SP2 cells increased angiogenic factors and led to increased angiogenesis. When adjusted for parental controls, densitometry analysis indicated that VEGF, FGFR and PDGFR were increased by 60,65 and 68\%, respectively, in Daoy-SP2 cells treated with pcMMP-9 when compared with Daoy-SP2 cells. (Supplementary Figure 1).

To further characterise the role of MMP-9 in SPARC-mediated inhibition of angiogenesis, we performed an in vitro angiogenic assay with Daoy-SP2 cells transfected with MMP-9 cDNA. Figures $4 \mathrm{~B}$ and $\mathrm{C}$ shows that ectopic expression of MMP-9 in Daoy-SP2 cells reversed the anti-angiogenic effects of these cells. We exogenously added human recombinant SPARC protein and determined weather Daoy tumour cells could induce tumour cell-induced angiogenesis. Our data indicate that addition of exogenous SPARC did not inhibit tumour cell-induced angiogenesis, unlike the forced expression of SPARC (Figure 4E). In addition, supplementing recombinant SPARC to Daoy-P cells, comparable with that of the SPARC levels in DAOY-SP2 cells, did not alter the angiogenic capability of these cells. Further addition of recombinant SPARC did not change the expression of MMP-9 and VEGF, as observed in the case of SPARC-overexpressed Dapy-SP2 cells (Figure 4D). These observations, taken together with the studies presented in Figure 2, confirm that SPARC 
A

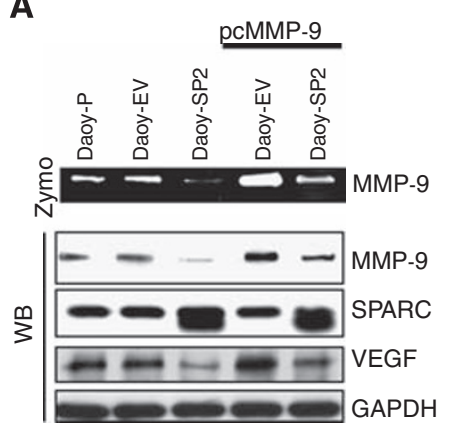

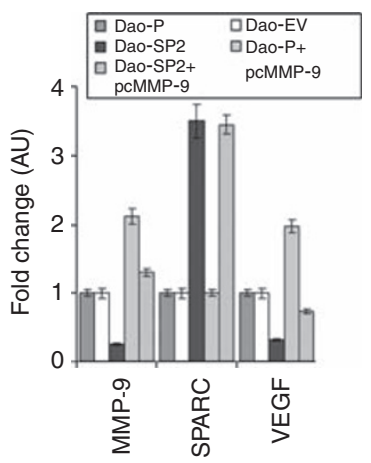

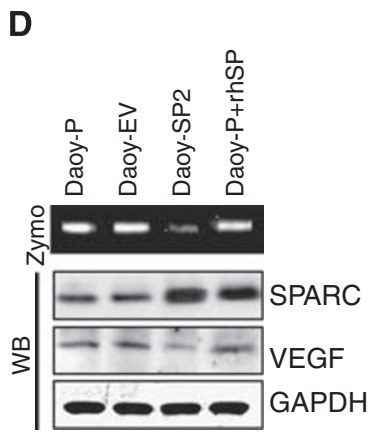

B
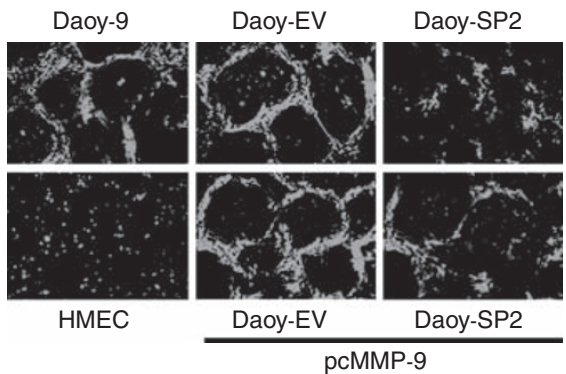

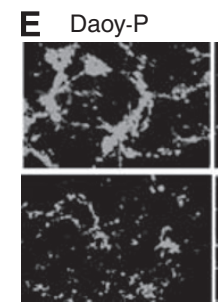

Daoy-SP2
Daoy-EV

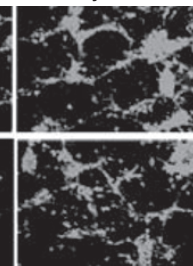

Daoy-P

+rhuSPARC
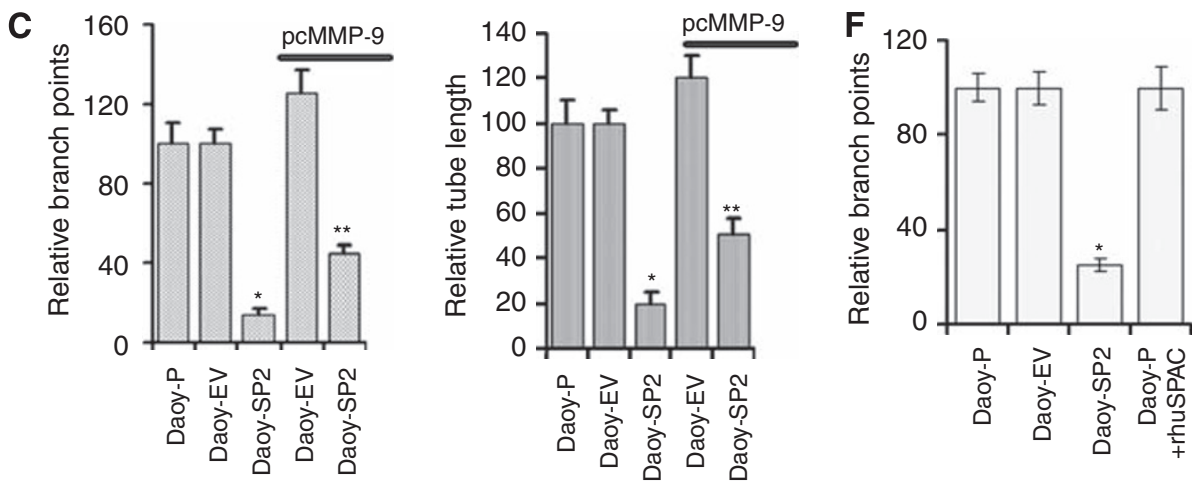

Figure 4 Overexpression of secreted protein acidic and rich in cysteine (SPARC) inhibits matrix metalloprotease-9 (MMP-9) activity and reduces vascular endothelial growth factor (VEGF) protein levels. (A) Daoy-P, Daoy-EV and Daoy-SP2 cells were transiently transfected with a vector encoding full-length MMP-9 cDNA (pcMMP-9). Gelatin zymography was carried out for MMP-9 activity. Western blot analysis was performed for MMP-9, SPARC and VEGF protein levels. The blots were stripped and reprobed with GAPDH antibody to detect total amounts of the respective proteins. (B) Daoy-P, Daoy-EV and Daoy-SP2 cells $\left(2 \times 10^{4}\right.$ per well) were seeded in eight-well chamber slides transfected with pcMMP-9 and allowed to grow for $24 \mathrm{~h}$. Then, the medium was removed and $4 \times 10^{4}$ HMEC cells were added. The cells were allowed to co-culture for $36 \mathrm{~h}$ the cell are fixed and performed immunofluorescence microscopy for factor-VIII as described in the 'Materials and methods' section and observed for angiogenic response. (C) Angiogenic result was quantified by counting the relative branch points and tube length in five different fields from three independent experiments. Columns, mean of triplicate experiments; bars, s.e.; $* P<0.01$, significant difference from Daoy parental cells; $* * P<0.01$, significant difference from Daoy-SP cells without pcMMP-9 treatment. (D) Parental Daoy cells were exogenously treated with recombinant human SPARC (rhuSPARC) for $36 \mathrm{~h}$. Gelatin zymography was carried out for MMP-9 activity. Western blot analysis was performed for SPARC and VEGF protein levels. The blots were stripped and reprobed with GAPDH antibody to detect total amounts of the respective proteins. (E) Daoy-P, Daoy-EV and Daoy-SP2 cells $\left(2 \times 10^{4}\right.$ per well) were seeded in eight-well chamber slides and Daoy-P cells were treated with rhuSPARC and allowed to grow for $24 \mathrm{~h}$ and performed co-culture assay as described above. (F) Angiogenic result was quantified by counting the relative branch points from three independent experiments. Columns, mean of triplicate experiments; bars, s.e. $* P<0.0$ I, significant difference from Daoy-P cells.

expression-mediated anti-angiogenic effects are due to altered gene expression rather than due to the expression of SPARC itself.

\section{Overexpression of SPARC in medulloblastoma cells inhibits tumourigenicity in nude mice}

To assess the therapeutic efficacy of SPARC expression, Daoy-P, Daoy-EV and Daoy-SP2 cells were injected intracranially into nude mice. Mice injected with Daoy-P and Daoy-EV cells developed tumours, became symptomatic within 6 weeks and were subse- quently killed. In striking contrast, mice injected with Daoy-SP2 cells survived for 180 days, which was the designated end point of the experiment. At this point, the animals were killed and their brains were examined for tumour growth. Tumours volumes were evaluated by measuring the maximum cross-sectional areas stained for anti-human-specific MHC class-I IgG (western blot analysis of MHC class-I IgG in tumours is shown (Supplementary Figure 3) in digitalised sections of cerebellum/tumour. Haematoxylin and eosin staining indicates significant tumour growth in brains of mice implanted with Daoy-P and Daoy-EV cells (Figure 5A). A corresponding statistically significant decrease 
A
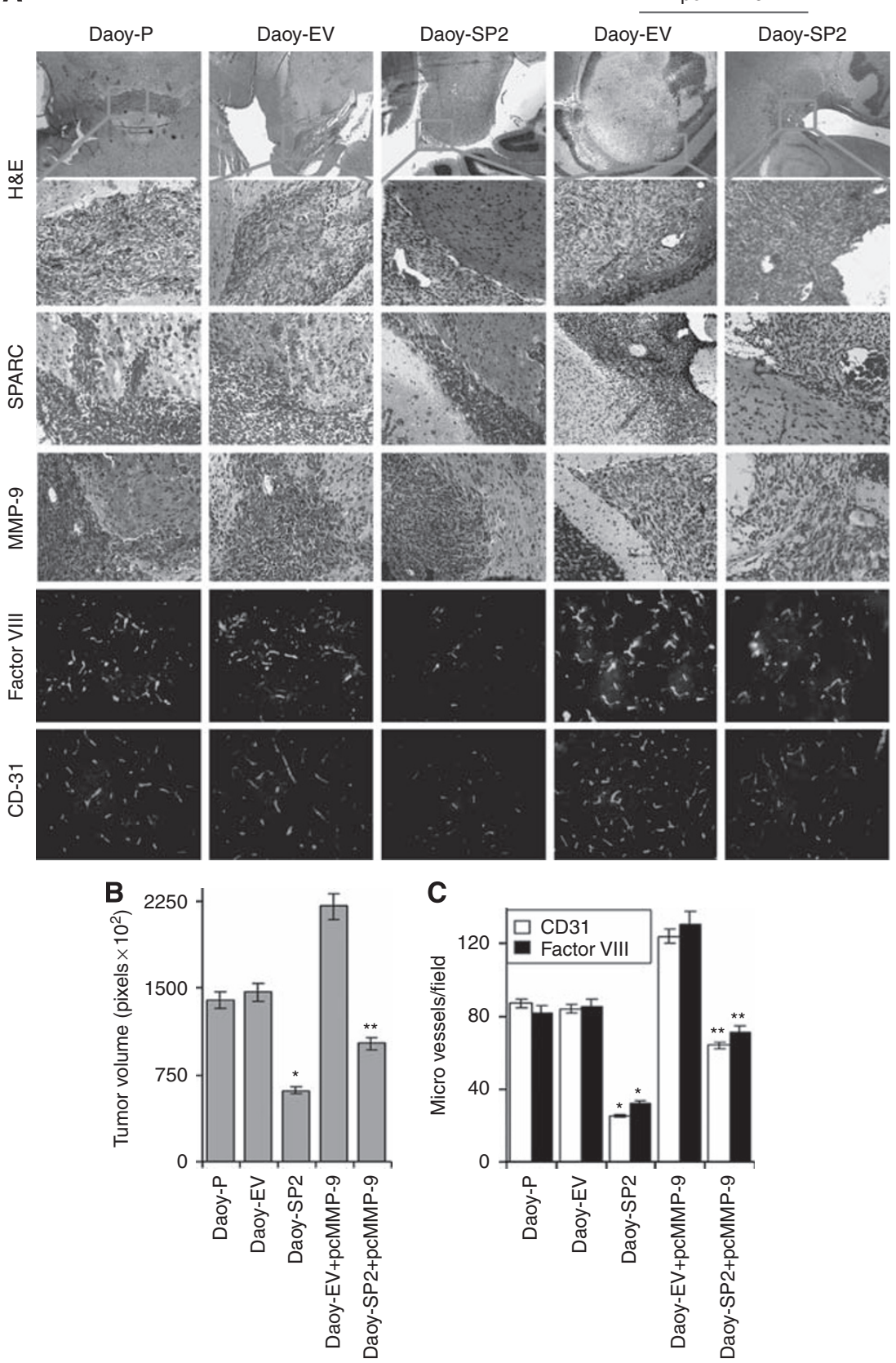

C

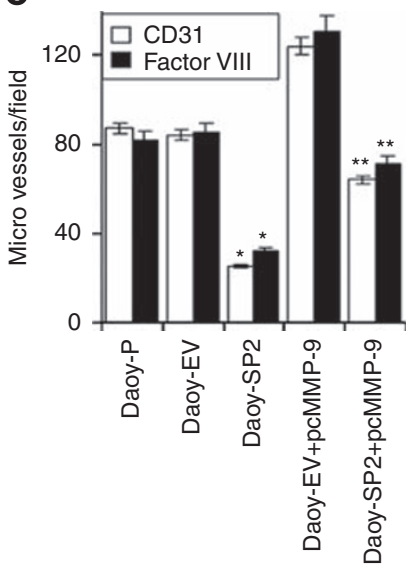

Figure 5 Secreted protein acidic and rich in cysteine (SPARC) inhibits medulloblastoma tumour growth in vivo. Medulloblastoma tumour sections from mice injected with Daoy-P, Daoy-EV, Daoy-SP2, Daoy-EV + PCMMP-9 and Daoy-SP2 + PCMMP-9 cells were analysed as described in the 'Materials and Methods' section. (A) Haematoxylin and eosin (H\&E) staining for the tumours: paraffin-embedded sections of tumours were used for immunohistochemical analysis for SPARC, MMP-9, CD-3I and factor-VIII was performed as described in the 'Materials and Methods' section. (B) Tumour volume was quantified and the results are presented in pixels. (C) CD3I (red) and factor-VIII (green) positive areas were counted and quantified as per microscopic field and results are represented. Columns, mean of triplicate experiments; bars, s.e.; $* P<0.0$ I, significant difference from Daoy parental cells. $* * * 0.05$, significant difference from Daoy-SP2 cells. The colour reproduction of the figure is available on the html full text version of the paper.

$(\sim 65 \%)$ in mean tumour volume was found in animals implanted with Daoy-SP2 $(n=6$; mean tumour volume $=54000$ pixels \pm 7000$)$ as compared with animals implanted with Daoy-EV $(n=6$; mean tumour volume $=156000$ pixels $\pm 16000 ; P<0.001)$.

To determine whether SPARC was expressed in vivo, brain sections were stained with a monoclonal antibody for human SPARC. Figure 5A indicates that tumour sections from Daoy-SP2 tumours showed more staining than did Daoy-P and Daoy-EV tumours. To assess whether MMP-9 inhibition mediated the anti-tumour effects of SPARC expression, we analysed angiogenesis in xenografts by histological analysis for CD-31, factor-VIII and MMP-9 expression (Figure 5A). Estimation of CD-31 and factor-VIII-positive areas in 20 randomly selected fields of tumours from Daoy-EV and Daoy-SP provided some measure of vascularity in the tumour sections (Figure 5C). Only a small fraction $(15-20 \%)$ of CD-31- or factor-VIII-positive areas remained in Daoy-SP2 tumours in comparison with the controls. It was also evident that the overexpression of SPARC in tumours caused a decrease in MMP-9 expression in these tumours (Figure 5A). 
We also analysed the effect of MMP-9 on the in vivo consequences of SPARC expression on medulloblastoma tumour formation in nude mice. Daoy-SP2 cells were transfected with MMP-9 cDNA and were injected into the brains of nude mice, and the formation of tumours was monitored. As shown in Figure 5A, ectopic expression of MMP-9 using a vector expressing full-length MMP-9 gene in Daoy-SP2 cells induced MMP-9 expression comparable with that of parental Daoy-P cells. The MMP-9 induction reversed SPARC-mediated tumour growth inhibition by $50 \%$, with a mean tumour volume of $30 \%$ of the empty vector control (Figure 5B). Accordingly, MMP-9, CD31 and factor-VIII expression were increased in the tumour sections in these mice compared with the tumour sections of mice with Daoy-SP2 cells (Figure 5C). These results are consistent with a role for MMP-9 in the SPARC-induced anti-angiogenic effect observed in vitro.

\section{DISCUSSION}

The SPARC is an ECM protein that influences the 'soil' in which tumours develop. The ECM is known to influence tumour growth directly (Netti et al, 2000; Hotary et al, 2003). The various activities associated with SPARC are thought to facilitate different steps in the formation of new vessels (Brekken and Sage, 2000). This study reports that SPARC expression results in a significant decrease in angiogenic capacities in vitro and in vivo and remarkably reduces in vivo tumourigenicity of medulloblastoma cells.

The contradictory reports regarding the role of SPARC in cell growth and tumour formation suggest that its effects are cell-type specific and may be dependent on concentration and ECM components. Therefore, the focus of this investigation was to determine the role of SPARC in medulloblastoma (i.e., the possibility of its use as a therapeutic target or agent). Using the Daoy cell line stably transfected with SPARC cDNA, we determined the contribution of SPARC in medulloblastoma tumour growth. SPARC protein and gene transcript levels were increased by about three-fold in Daoy-SP clones compared with Daoy-P and Daoy-EV stable clones, as determined by western blotting and reverse transcriptase PCR analyses. The SPARC expression inhibited tumour cell-induced tube formation by endothelial cells in an in vitro co-culture assay and abrogated induction of angiogenesis in a dorsal window air sac assay in vivo. To investigate the function of SPARC in the regulation of medulloblastoma tumour growth in vivo, Daoy-SP cells were compared for their ability to form tumours in an intracranial model. Overexpression of full-length SPARC significantly reduced tumour size in xenografts. Therefore, in medulloblastoma, SPARC expression is inversely correlated with malignant phenotype. Previous studies have indicated that SPARC contributes to the regulation of tumour formation, although its role seems to be cell-type specific. The SPARC exerts growth inhibitory activity on immortalised ovarian cancer cells in vitro and in mouse xenograft explants (Abeysinghe et al, 2003). Similarly, the tumour growth of glioma cells overexpressing SPARC was delayed in vivo (Schultz et al, 2002). An inhibitory effect of SPARC on proliferation and migration has been found in breast and ovarian carcinoma cells (Dhanesuan et al, 2002). Infection of MDA-231 breast carcinoma cells with osteonectin decreased the in vitro invasion of these cells through Matrigel (Koblinski et al, 2005). Overexpression of SPARC by ovarian carcinoma cells led to increased tumour cell apoptosis, and the levels of SPARC were inversely correlated with tumour progression in vivo (Yiu et al, 2001). The growth of Lewis lung carcinoma and B-cell lymphoma was enhanced in mice lacking endogenous SPARC (Brekken et al, 2003). Pancreatic tumour growth was enhanced in mice lacking endogenous SPARC (Puolakkainen et al, 2004).

Tumour growth has been shown to depend on angiogenesis. Our study demonstrates that the anti-tumour effect of SPARC expression in vivo is mediated, at least in part, by anti-vascular effects. The reduced tumour growth in tumours formed with Daoy cells expressing SPARC cDNA was associated with a decrease in angiogenesis. Medulloblastomas produce a wide range of angiogenic factors that are likely to have a direct role in tumour growth (Pavlakovic et al, 2001a). Besides its effect on proliferation, SPARC is thought to function in tissue remodelling and angiogenesis. However, the role of SPARC on tumour cell-induced angiogenesis has not been clearly established. Our results show that there was reduced capillary tube formation when endothelial cells were grown in the presence of Daoy-SP cells as compared with the parental and vector controls in an in vitro angiogenic assay. In addition to these in vitro anti-angiogenic activities, SPARC seems to be anti-angiogenic in vivo, as demonstrated by the suppression of neovascularisation in the dorsal window air sac assay. Analysis of tumours formed with SPARC-overexpressing clones showed that SPARC overexpression reduces vessel density as determined by CD31 or factor-VIII staining. These results confirm that SPARC is an inhibitor of tumour angiogenesis in vivo.

A variety of growth factors can stimulate angiogenesis. The most important angiogenesis stimulators are VEGF (Veikkola and Alitalo, 1999) and bFGF (Pavlakovic et al, 2001b). Tumour cells may overexpress one or more of these angiogenic factors, which in turn function synergistically to promote tumour growth. It has been reported that some of the primitive neuroectodermal tumours, which include medulloblastoma, show immunoreactivity for VEGF and bFGF (Brem et al, 1992; Pietsch et al, 1997). In another study, as determined by immunohistochemistry, VEGF was expressed in all tested medulloblastoma tumours, suggesting that inhibition of VEGF in medulloblastomas may result in the inhibition of angiogenesis, as well as in tumour growth and progression (Ozer et al, 2004). The relationship between SPARC in tumour cells and the expression of angiogenic molecules, as evaluated using a PCR array, indicated that several angiogenic molecules were reduced in Daoy-SP cells compared with controls. Similarly, results from the western blot analysis also showed the downregulation of some potent angiogenic molecules, including MMP-9, VEGF, PDGFR and FGF. These results suggest that SPARC expression alters the angiogenic balance in the tumour microenvironment by altering the expression of a complex array of inhibitors and stimuli. Growth factors, such as VEGF or PDGF, act directly on endothelial cells and/or activate inflammatory cells (monocytes and T lymphocytes), which in turn synthesise angiogenic factors. Previous studies demonstrated that SPARC regulates additional components and coordinates the activity of growth factors on endothelial cell proliferation and migration. The SPARC antagonised the migratory response of endothelial cells to bFGF without the binding of SPARC to bFGF or the blocking of the ligand-receptor interaction (Hasselaar and Sage, 1992). The SPARC modulates glioma growth by altering the tumour microenvironment and suppressing tumour vascularity through suppression of VEGF expression and secretion. (Yunker et al, 2008). In this context, the suppression of angiogenesis-mediated tumour growth by SPARC in medulloblastoma seems to be the consequence of its ability to inhibit the expression of angiogenic factors such as MMP-9, bFGF and VEGF in tumour tissues, which may in turn inhibit capillary infiltration into tumours. We show that MMP-9 expression in SPARC-overexpressed clones restored VEGF expression and SPARC-induced anti-angiogenic effect. A positive feedback regulation between MMP-9 and VEGF was reported in retinal pigment epithelial cells (Hollborn et al, 2007). Our PCR array analysis also indicates that MMP-9 induction induced HIF expression (Supplementary Figure 1), a transcriptional factor for VEGF (Hellwig-Burgel et al, 2005) that probably induced VEGF levels.

Our results indicate that SPARC expression inhibits tumour growth in vivo. We also show that this inhibition of tumour growth could be mediated in part by inhibition of MMP-9. Our data also 
indicate that MMP-9 and VEGF levels were maximally inhibited in Daoy-SP2 cells, which show an increased anti-angiogenic effect compared with other clones (Supplementary Figure 2). Our studies indicate MMP-9 induction in Daoy-EV cell-induced angiogenesis, as indicated by an increase in branch points and enhanced tumour growth by $50 \%$ compared with that of controls. However, MMP-9 expression in Daoy-SP2 cells reversed the SPARC-mediated inhibition of anti-angiogenic effect and tumour growth by only about $50 \%$ compared with that of tumour cell-induced angiogenesis and tumour growth in vivo induced by Daoy-SP2 cells, although western blot analysis for MMP-9 indicated that transfection with plasmid expressing MMP-9 cDNA in Daoy-SP2 cells restored the expression of MMP-9 to that of parental cells (Figure 4A). In addition, western blot analysis of VEGF expression indicated that VEGF levels in MMP-9-induced Daoy-EV cells are almost two-fold higher than that of parental control cells, which probably contributed to the enhanced tumour growth induced by these cells. However, VEGF expression in MMP-9-induced Daoy-SP cells was restored to only about $70 \%$. This suggests that factors other than MMP-9 and VEGF are involved in SPARC-mediated inhibition of tumour growth. Previous studies also indicate that SPARC alters the expression of several genes involved in cell-cycle progression, signalling and migration (Golembieski and Rempel, 2002). Moreover, we also show that SPARC inhibition with SPARC siRNA or antibody in vitro did not reverse the effect of
SPARC-mediated inhibition of angiogenesis. In addition, exogenous addition of recombinant SPARC did not alter angiogenesis or MMP-9 and VEGF levels (Figure 4D). These studies suggest that decreased angiogenesis in SPARC-overexpressed cells could be due to SPARC-induced altered cellular composition rather than the effect of SPARC expression itself.

Little progress has been made in the development of molecular targeted therapies for paediatric malignancies. This study provides an insight into the possible functional roles of SPARC in medulloblastoma tumour angiogenesis, and the data demonstrate that SPARC expression is inversely correlated with medulloblastoma tumour growth in vivo.

\section{ACKNOWLEDGEMENTS}

We acknowledge Shellee Abraham for paper preparation, and Sushma Jasti and Diana Meister for paper review. This research was supported by National Cancer Institute Grant CA132853 (to $\mathrm{SL})$. The contents of this paper are solely the responsibility of the authors and do not necessarily represent the official views of NIH.

Supplementary Information accompanies the paper on British Journal of Cancer website (http://www.nature.com/bjc)

\section{REFERENCES}

Abeysinghe HR, Cao Q, Xu J, Pollock S, Veyberman Y, Guckert NL, Keng P, Wang N (2003) THY1 expression is associated with tumor suppression of human ovarian cancer. Cancer Genet Cytogenet 143: 125-132

Arnold S, Mira E, Muneer S, Korpanty G, Beck AW, Holloway SE, Manes S, Brekken RA (2008) Forced expression of MMP9 rescues the loss of angiogenesis and abrogates metastasis of pancreatic tumors triggered by the absence of host SPARC. Exp Biol Med (Maywood) 233: 860-873

Assimakopoulou M, Sotiropoulou-Bonikou G, Maraziotis T, Papadakis N, Varakis I (1997) Microvessel density in brain tumors. Anticancer Res 17: $4747-4753$

Bellahcene A, Castronovo V (1995) Increased expression of osteonectin and osteopontin, two bone matrix proteins, in human breast cancer. $A m J$ Pathol 146: $95-100$

Bhoopathi P, Chetty C, Kunigal S, Vanamala SK, Rao JS, Lakka SS (2008) Blockade of tumor growth due to matrix metalloproteinase- 9 inhibition is mediated by sequential activation of betal-integrin, ERK, and NF-kappaB. J Biol Chem 283: $1545-1552$

Bornstein P, Sage EH (2002) Matricellular proteins: extracellular modulators of cell function. Curr Opin Cell Biol 14: 608-616

Bradshaw AD, Sage EH (2001) SPARC, a matricellular protein that functions in cellular differentiation and tissue response to injury. J Clin Invest 107: 1049 - 1054

Brekken RA, Puolakkainen P, Graves DC, Workman G, Lubkin SR, Sage EH (2003) Enhanced growth of tumors in SPARC null mice is associated with changes in the ECM. J Clin Invest 111: 487-495

Brekken RA, Sage EH (2000) SPARC, a matricellular protein: at the crossroads of cell-matrix. Matrix Biol 19: 569-580

Brekken RA, Sage EH (2001) SPARC, a matricellular protein: at the crossroads of cell-matrix communication. Matrix Biol 19: 816-827

Brem S, Tsanaclis AM, Gately S, Gross JL, Herblin WF (1992) Immunolocalization of basic fibroblast growth factor to the microvasculature of human brain tumors. Cancer 70: 2673-2680

Chandrasekaran V, Ambati J, Ambati BK, Taylor EW (2007) Molecular docking and analysis of interactions between vascular endothelial growth factor (VEGF) and SPARC protein. J Mol Graph Model 26: 775-782

Chetty C, Bhoopathi P, Lakka SS, Rao JS (2007) MMP-2 siRNA induced Fas/CD95-mediated extrinsic II apoptotic pathway in the A549 lung adenocarcinoma cell line. Oncogene 26: 7675-7683

Chetty C, Lakka SS, Bhoopathi P, Kunigal S, Geiss R, Rao JS (2008) Tissue inhibitor of metalloproteinase 3 suppresses tumor angiogenesis in matrix metalloproteinase 2-down-regulated lung cancer. Cancer Res 68: $4736-4745$
Chlenski A, Liu S, Crawford SE, Volpert OV, DeVries GH, Evangelista A, Yang Q, Salwen HR, Farrer R, Bray J, Cohn SL (2002) SPARC is a key Schwannian-derived inhibitor controlling neuroblastoma tumor angiogenesis. Cancer Res 62: 7357-7363

Chlenski A, Liu S, Guerrero LJ, Yang Q, Tian Y, Salwen HR, Zage P, Cohn SL (2006) SPARC expression is associated with impaired tumor growth, inhibited angiogenesis and changes in the extracellular matrix. Int $J$ Cancer 118: $310-316$

Dhanesuan N, Sharp JA, Blick T, Price JT, Thompson EW (2002) Doxycycline-inducible expression of SPARC/Osteonectin/BM40 in MDA-MB-231 human breast cancer cells results in growth inhibition. Breast Cancer Res Treat 75: 73-85

Ding Q, Grammer JR, Nelson MA, Guan JL, Stewart Jr JE, Gladson CL (2005) p27Kip1 and cyclin D1 are necessary for focal adhesion kinase regulation of cell cycle progression in glioblastoma cells propagated in vitro and in vivo in the scid mouse brain. J Biol Chem 280: 6802-6815

Eberhart CG, Kepner JL, Goldthwaite PT, Kun LE, Duffner PK, Friedman HS, Strother DR, Burger PC (2002) Histopathologic grading of medulloblastomas: a Pediatric Oncology Group study. Cancer 94: $552-560$

Framson PE, Sage EH (2004) SPARC and tumor growth: where the seed meets the soil? J Cell Biochem 92: 679-690

Francki A, Bradshaw AD, Bassuk JA, Howe CC, Couser WG, Sage EH (1999) SPARC regulates the expression of collagen type I and transforming growth factor-betal in mesangial cells. J Biol Chem 274: 32145-32152

Francki A, Motamed K, McClure TD, Kaya M, Murri C, Blake DJ, Carbon JG, Sage EH (2003) SPARC regulates cell cycle progression in mesangial cells via its inhibition of IGF-dependent signaling. J Cell Biochem 88: $802-811$

Golembieski WA, Rempel SA (2002) cDNA array analysis of SPARCmodulated changes in glioma gene expression. J Neurooncol 60: 213-226

Gondi CS, Lakka SS, Dinh D, Olivero W, Gujrati M, Rao JS (2004) Downregulation of uPA, uPAR and MMP-9 using small, interfering, hairpin RNA (siRNA) inhibits glioma cell invasion, angiogenesis and tumor growth. Neuron Glia Biol 1: 165-176

Guerreiro AS, Fattet S, Fischer B, Shalaby T, Jackson SP, Schoenwaelder SM, Grotzer MA, Delattre O, Arcaro A (2008) Targeting the PI3K p110alpha isoform inhibits medulloblastoma proliferation, chemoresistance, and migration. Clin Cancer Res 14: 6761-6769

Hasselaar P, Sage EH (1992) SPARC antagonizes the effect of basic fibroblast growth factor on the migration of bovine aortic endothelial cells. J Cell Biochem 49: 272-283 
Hellwig-Burgel T, Stiehl DP, Wagner AE, Metzen E, Jelkmann W (2005) Review: hypoxia-inducible factor-1 (HIF-1): a novel transcription factor in immune reactions. J Interferon Cytokine Res 25: 297-310

Hollborn M, Stathopoulos C, Steffen A, Wiedemann P, Kohen L, Bringmann A (2007) Positive feedback regulation between MMP-9 and VEGF in human RPE cells. Invest Ophthalmol Vis Sci 48: 4360-4367

Hotary KB, Allen ED, Brooks PC, Datta NS, Long MW, Weiss SJ (2003) Membrane type I matrix metalloproteinase usurps tumor growth control imposed by the three-dimensional extracellular matrix. Cell 114: $33-45$

Koblinski JE, Kaplan-Singer BR, VanOsdol SJ, Wu M, Engbring JA, Wang S, Goldsmith CM, Piper JT, Vostal JG, Harms JF, Welch DR, Kleinman HK (2005) Endogenous osteonectin/SPARC/BM-40 expression inhibits MDA-MB-231 breast cancer cell metastasis. Cancer Res 65: 7370-7377

Kupprion C, Motamed K, Sage EH (1998) SPARC (BM-40, osteonectin) inhibits the mitogenic effect of vascular endothelial growth factor on microvascular endothelial cells. J Biol Chem 273: 29635-29640

Lakka SS, Gondi CS, Dinh DH, Olivero WC, Gujrati M, Rao VH, Sioka C, Rao JS (2005) Specific interference of uPAR and MMP-9 gene expression induced by double-stranded RNA results in decreased invasion, tumor growth and angiogenesis in gliomas. J Biol Chem 280: 21882-21892

Lau CP, Poon RT, Cheung ST, Yu WC, Fan ST (2006) SPARC and Hevin expression correlate with tumour angiogenesis in hepatocellular carcinoma. J Pathol 210: 459-468

Ledda MF, Adris S, Bravo AI, Kairiyama C, Bover L, Chernajovsky Y, Mordoh J, Podhajcer OL (1997) Suppression of SPARC expression by antisense RNA abrogates the tumorigenicity of human melanoma cells. Nat Med 3: $171-176$

Mohanam S, Jasti SL, Kondraganti SR, Chandrasekar N, Kin Y, Fuller GN, Lakka SS, Kyritsis AP, Dinh DH, Olivero WC, Gujrati M, Yung WK, Rao JS (2001) Stable transfection of urokinase-type plasminogen activator antisense construct modulates invasion of human glioblastoma cells. Clin Cancer Res 7: 2519-2526

Netti PA, Berk DA, Swartz MA, Grodzinsky AJ, Jain RK (2000) Role of extracellular matrix assembly in interstitial transport in solid tumors. Cancer Res 60: 2497-2503

Ozer E, Sarialioglu F, Cetingoz R, Yuceer N, Cakmakci H, Ozkal S, Olgun N, Uysal K, Corapcioglu F, Canda S (2004) Prognostic significance of anaplasia and angiogenesis in childhood medulloblastoma: a pediatric oncology group study. Pathol Res Pract 200: 501 - 509

Packer RJ (1999) Childhood medulloblastoma: progress and future challenges. Brain Dev 21: 75-81

Packer RJ, Vezina G (2008) Management of and prognosis with medulloblastoma: therapy at a crossroads. Arch Neurol 65: 1419-1424

Pavlakovic H, Havers W, Schweigerer L (2001a) Multiple angiogenesis stimulators in a single malignancy: implications for anti-angiogenic tumour therapy. Angiogenesis 4: 259-262

Pavlakovic H, Von Schutz V, Rossler J, Koscielniak E, Havers W, Schweigerer L (2001b) Quantification of angiogenesis stimulators in children with solid malignancies. Int J Cancer 92: 756-760

Pietsch T, Valter MM, Wolf HK, von Deimling A, Huang HJ, Cavenee WK, Wiestler OD (1997) Expression and distribution of vascular endothelial growth factor protein in human brain tumors. Acta Neuropathol (Berl) 93: $109-117$
Porte H, Chastre E, Prevot S, Nordlinger B, Empereur S, Basset P, Chambon P, Gespach C (1995) Neoplastic progression of human colorectal cancer is associated with overexpression of the stromelysin-3 and BM-40/SPARC genes. Int J Cancer 64: 70-75

Puolakkainen PA, Brekken RA, Muneer S, Sage EH (2004) Enhanced growth of pancreatic tumors in SPARC-null mice is associated with decreased deposition of extracellular matrix and reduced tumor cell apoptosis. Mol Cancer Res 2: 215-224

Raines EW, Lane TF, Iruela-Arispe ML, Ross R, Sage EH (1992) The extracellular glycoprotein SPARC interacts with platelet-derived growth factor (PDGF)-AB and $-\mathrm{BB}$ and inhibits the binding of PDGF to its receptors. Proc Natl Acad Sci USA 89: 1281 - 1285

Rao JS, Bhoopathi P, Chetty C, Gujrati M, Lakka SS (2007) Matrix metalloproteinase- 9 short interfering RNA induced senescence resulting in inhibition of medulloblastoma growth via p16INK4 and mitogenactivated protein kinase pathway. Cancer Res 67: 4956-4964

Rempel SA, Ge S, Gutierrez JA (1999) SPARC: a potential diagnostic marker of invasive meningiomas. Clin Cancer Res 5: 237-241

Ris MD, Packer R, Goldwein J, Jones-Wallace D, Boyett JM (2001) Intellectual outcome after reduced-dose radiation therapy plus adjuvant chemotherapy for medulloblastoma: a Children's Cancer Group study. J Clin Oncol 19: 3470 - 3476

Sage H, Johnson C, Bornstein P (1984) Characterization of a novel serum albumin-binding glycoprotein secreted by endothelial cells in culture. J Biol Chem 259: $3993-4007$

Schultz C, Lemke N, Ge S, Golembieski WA, Rempel SA (2002) Secreted protein acidic and rich in cysteine promotes glioma invasion and delays tumor growth in vivo. Cancer Res 62: 6270 - 6277

Shankavaram UT, DeWitt DL, Funk SE, Sage EH, Wahl LM (1997) Regulation of human monocyte matrix metalloproteinases by SPARC. J Cell Physiol 173: 327-334

Veikkola T, Alitalo K (1999) VEGFs, receptors and angiogenesis. Semin Cancer Biol 9: 211-220

Workman P, Balmain A, Hickman JA, McNally NJ, Rohas AM, Mitchison NA, Pierrepoint CG, Raymond R, Rowlatt C, Stephens TC (1988) UKCCCR guidelines for the welfare of animals in experimental neoplasia Lab Anim 22: 195 - 201

Yan Q, Sage EH (1999) SPARC, a matricellular glycoprotein with important biological functions. J Histochem Cytochem 47: 1495-1506

Yiu GK, Chan WY, Ng SW, Chan PS, Cheung KK, Berkowitz RS, Mok SC (2001) SPARC (secreted protein acidic and rich in cysteine) induces apoptosis in ovarian cancer cells. Am J Pathol 159: 609-622

Yunker CK, Golembieski W, Lemke N, Schultz CR, Cazacu S, Brodie C, Rempel SA (2008) SPARC-induced increase in glioma matrix and decrease in vascularity are associated with reduced VEGF expression and secretion. Int J Cancer 122: 2735-2743

Zeltzer PM, Boyett JM, Finlay JL, Albright AL, Rorke LB, Milstein JM, Allen JC, Stevens KR, Stanley P, Li H, Wisoff JH, Geyer JR, Guire-Cullen P, Stehbens JA, Shurin SB, Packer RJ (1999) Metastasis stage, adjuvant treatment, and residual tumor are prognostic factors for medulloblastoma in children: conclusions from the Children's Cancer Group 921 randomized phase III study. J Clin Oncol 17: $832-845$ 